\title{
A New Marketing Strategy for E-Commerce
}

\author{
Choong Y. Lee \\ Pittsburg State University, Pittsburg, KS 66762, USA
}

\author{
lee@pittstate.edu
}

\begin{abstract}
The purpose of this article is to explore e-commerce issues, such as marketing and logistics problems, and create viable recommendations. The issues that e-commerce faces will be examined through the marketing mix. Exploring the ideas of product, place, price and promotion, and applying them to ecommerce problems is the main focal point of this article. It is believed that the four concepts of the marketing mix equally play a critical part in the success of e-commerce. Therefore, concentrating on these concepts will prove to be of the utmost importance as an e-commerce provider.
\end{abstract}

\section{Introduction}

The Internet is not a new concept it has been around for over 30 years. The U. S. go vernment developed the Internet to do research and to connect university computers throughout the country. In the early 1980's, the government split the Internet into two sections, one for government use and one that was designed to promote education and research. Since that time the Internet has boomed, reaching over 30 million households and organizations around the world. As the Internet expanded it moved into doing business orientated functions, such as selling products over the Internet. This concept has become known as e-commerce. E-commerce today represents a 300 billion dollar industry. This is why it is an important area to be concerned with from a businesses standpoint. This huge market is an awesome place for organizations to promote themselves and to contract business through. Since the expansion of e-commerce, organizations have run themselves thin; the demand from customers is so great, that many sites can't keep up with the demand. Not being able to match the demand in the future will destroy the confidence of customers, in this already intangible means of commerce. For this means of commerce to continue to attract customers and keep them, they need to focus on satisfying each customer. On the other hand there is fierce competition and creating demand is essential for many companies to survive. Applying the marketing mix to e-commerce issues, recommendations can be drawn.

\section{Literary Review}

There are numerous articles that deal with both the marketing mix and e-commerce, but none attempt to combine them. According to Marcia Jedd, the biggest problem with e-commerce now and in the future is delivery (Jedd, 2000). Residential deliveries cost delivery companies three times as much as deliveries to business, because residential areas are less dense (Jedd, 2000). Also dealing with delivery, the

Material published as part of these proceedings, either on-line or in print, is copyrighted by Informing Science. Permission to make digital or paper copy of part or all of these works for personal or classroom use is granted without fee provided that the copies are not made or distributed for profit or commercial advantage AND that copies 1) bear this notice in full and 2) give the full citation on the first page. It is permissible to abstract these works so long as credit is given. To copy in all other cases or to republish or to post on a server or to redistribute to lists requires specific permission from the publisher at Publisher@InformingScience.org residential deliveries are much more expensive due to inability to create economies of scale (Jedd, 2000). Some experts believe that information technology is a must in improving logistics and supply chains (Ayers, 1999). In recent years, numerous types of information systems have been developed to increase efficiency of logistics, such 
as warehousing, inventory, and delivery operations (Ayers, 1999).

\section{Advantages of E-commerce}

E-commerce has many advantages for most organizations that choose to use this means of operation. One of the biggest advantages is it allows reduced warehousing and inventory cost due automation. Ecommerce is also independent of size, for the most part; any organization can operate over the Internet. The Internet also reduces the adva ntage of large companies over small companies, because it somewhat levels the playing field (Wilder, 1998). Organizations can reach global areas that would have been otherwise difficult. This is good because it allows global communication and products to people who can't purchase your product in their home region. E-commerce companies will also increase their accessibility, it creates a twenty-four hour operation, and this allows people to shop when it's convenient to them (Pallab, 1996). E-commerce also increases advertising and it allows a broader scope of segments. It also is self-selective, me aning people who are on your site are interested; they want to learn about your organization or product (Wehling, 1996). Maybe the biggest advantage of e-commerce is its one to one marketing (Wehling, 1996). E-commerce also allows organizations to gather information on its custo $\mathrm{m}$ ers or potential customers. It's also a unique form of marketing research that is fairly inexpensive (Pallab, 1996).

\section{Problems of E-commerce}

With such rapid growth of the Internet, distribution has become a difficult task for companies to manage. With such an increase in demand, many companies are not able to handle the number of orders efficiently. The demand is putting a burden on the inventory handling process, packaging, and residential delivery functions.

Some of the distribution problems are not the fault of e-commerce companies, but the delivery service they choose. The delivery companies are not handling the increase in demand efficiently, but their customers blame the e-commerce company. This problem is vital for an organization to overcome; custo $\mathrm{m}-$ ers will evaluate the total experience of the online purchasing as a whole. For example, if a product is purchased, and the e-commerce company does every thing correctly but the shipper doesn't perform their task properly, it will affect the technical outcome of the satisfaction level. Customers will rate the transaction as a whole, so choosing the correct shipper is vital.

Many transactions are done via the Internet, which can take an especially long time. Cus tomers will at some point forget the transaction if they are required to wait extended periods, especially if the product is accessible at local retail vendors. Managing the time required for a customer to complete a transaction affects potential sales (Harvard Business Review, 2000). Many times why customers don't finish the transaction is due to extended wait of finalizing the transaction (Harvard Business Review, 2000).

The lack automated inventory and shipping systems are problems for e-commerce companies. This lack of technology really stresses the ability of a firm to meet the demands of customers in a concise time period. According to a Federal Express executive, many companies will crash before they upgrade to automation logistic systems (Wilson, 1999). Many of the early e-commerce companies outsource their order checking and distribution functions (Haywood, 1989). This is proved to be a problem for some companies because of shipping cost has proved to be a big deterrent of customers buying online and wareho use and distribution systems were not set up to handle e-commerce business.

Internet sites can also be hard to find for some patrons, which can deter potential custo mers from buying online. Even if the potential customer knows what they want, finding the web site that offers the best price can be a lengthy task. Using search engines such as Yahoo or Excite can help, but they search in a very broad manner, sometimes it takes too long to find the web site. This may cause buyers to buy the 
product at local retail vendor (Mardesich, 1999). According to Resource Marketing, their research co nfirms this problem. In their recent study of 45 search sites, only one third proved to generate relevant sites (Mardesich, 1999).

When a customer does find a product that they want, it is difficult to get a physical grasp of the product (Mardesich, 1999). There is a lot of intangibility when purchasing online, such as buying items that are sold in sizes. Not being able to try on products is a barrier that e-commerce must overcome to increase sales to compete with local retail outlets.

Although e-commerce separates itself from the traditional retail outlet, it still must compete with them. For example, when purchasing an item online, the price of the actual good offered is often cheaper online, but the high cost of shipping decreases the advantage for buying online. If a compact disk cost five dollars on line and then cost six dollars to ship, it ends up costing about the same amount as priced in local retail outlets (Wilson, 1999).

Customer service online is a current drawback of e-commerce. Many companies have poor online service. According to Resource Marketing, their results show that only 10 out of 45 sites offered fair warranty and return services (Mardesich, 1999).

E-commerce companies also must deal with seasonal changes; their inability to handle high demand periods, such as Christmas is an important challenge. Not handling the demand increase effectively reduces the confidence of online buyers or potential online buyers.

Some e-commerce companies have been involved in unethical marketing tactics. E-commerce company, Buy.com has been under fire for false advertising (Foster, 1999). With Buy.com using tactics such as, bait-and-switch, it reduces the image of e-commerce as a whole. Buy.com is also known to post really low prices to lure customers into the site, and then tell the customers that the promotion has expired (Foster, 1999). Some companies are also selling their customer list, creating dissatisfaction among current online buyers. External factors are something that affects the entire industry.

\section{Applying the Marketing Mix}

\section{Product}

One of the main issues of concern is the intangibility of purchasing online. The intangibility is caused by not being able to focus on tangible aspects when purchasing online. The customer can't actually touch or feel a product, which increases the risk of the purchase. The key to reducing intangibility is creating tangible cues that the customer recognizes. Creating a positive brand image will reduce the risk (Kurtz, 1998). For example, buying a product that has a quality image will reduce the risk for custo $\mathrm{m}$ ers. Companies need to focus on creating a positive and reliable brand name.

Stressing the actual or perceived benefits received from the product can also reduce intangibility. Relaying to the customer that they will be very satisfied with the benefits of the product is important. For example if a company sales golf clubs online, they want to stress concept that they will hit the ball farther and straighter, which will allow the person to increase their enjoyment when playing golf. Also, focusing on the actual components of the product is important. Explaining the benefits of the clubs grip and shaft in the product will also redirect the attention away from the intangible aspects.

Focusing on advantages of buying on line is also important for companies to achieve increased sales. On the web site it is important to convey the convenience of buying your product online. Conveying the message that your product is conveniently accessible, lets the customer understand that they don't need to stand in lines or deal with other customers. Long lines and other customers can keep customers 


\section{New Marketing Strategy for E-Commerce}

from buying or decrease the amount they are willing to purchase. Explaining the convenience of buying on line is a good way to reduce the problem of intangibility.

There are some instances where the convenience of online buying can be diminished. When the customer finally decides to purchase a good it's important for this transaction to be quick and concise (Foster, 1999). The quicker this action can be done accurately the better. If it takes a long time for this action, customers may defect and buy the product through a local retail outlet. Companies need to be aware of this and implement the proper technology to assure that this barrier is minimized.

Since products can't be seen in person, it creates a barrier between the company and the buyer. A possible way to overcome this factor is through technology. By providing actual pictures of the product, it will allow the customer to get a better understanding of the products. If the web site has high quality pictures, it will reduce the perceive risk, which can increase the sales for a company.

Products that are produced in different sizes, such as clothing, create a problem for companies. Custo mers that want to buy the product may not because they are not sure how the product will fit. This creates a problem for the company, it is important to have a lenient return policy, but even more importantly, they should purchase software that helps in sizing (Mardesich, 1999). This software will allow customers to input their measurements and the web site will recommend which size is best for them (Mardesich, 1999). This type of technology will reduce the risk involved, which will increase the number of products sold.

The service involved is also a barrier that must be understood and managed correctly (Mardesich, 1999). Having a lenient or fair return system will lower the perceived risk involved. The customer is more likely to purchase the product if they know that returning the product will be of minimal hassle and at no expense. Providing the high service is directly related to increasing sales. Companies should also pay the postage to have the product returned. Paying the postage will again, lower the perceived risk, will most likely help in stimulating sales. Of course, this can only prove to be beneficial if the product doesn't have a high defective rate.

\section{Place}

Some of the distribution problems are uncontrollable at this point in the life cycle of the Internet. In some instances the problem of delivering the product to the customers isn't the fault of the online company. Nearly every online company does choose to outsource the delivery function, which at this point is the most efficient. Online customers are having a difficult time satisfying their customers, because of something that isn't their fault. The company that the y select to ship their product isn't handling the demand. For high volume companies this can be easier to solve.

There is a definite need for companies to manage the relationship with the shipping companies. The bigger the company the more power it posses in the supply chain. They have the ability to hurt the shipping company by choosing to change shippers. Even though there are few shipping companies, the online company can claim they will switch, if their quality of service doesn't increase. By threatening a switch, it will hopefully create better service for a large company.

One of the biggest problems with online buying is the lack of automated inventory and warehousing systems (Wilson, 1999). The lack of automation really hinders in the efficiency and speed of meeting the customer needs. For small companies, it is a good idea to outsource the warehouse and distribution functions, because they aren't efficient enough to meet customers' needs. Outsourcing will reduce the actual profit, because it is expensive (Wilson, 1999). Over time it will prove to be beneficial, because it will help in building loyalty. The most important thing to understand is choo sing the correct outsourcer. Companies want to pick an outsourcer that isn't overbooked with clients so they can efficiently handle demand requirements. 
Large online companies really need to consider automating the inventory and warehousing functions. This may be the best way to stay competitive in the future. The use of logistics consultants is a good strategy to assist in choosing an automated system that matches company needs.

Large companies that use outsourcers should look into instituting their own logistics system. Even though it is working for the company, it may be reducing profit (Wilson, 1999). Each part of the supply chain makes a small profit in the online commerce. The actual sale of the product makes a small profit, the warehousing makes a small profit, and the packager makes a small profit. Add up these areas and that means there is a larger profit to be made by taking over these functions (Wilson, 1999). If a company can do these functions themselves they will increase their profits, because they can do it cheaper than an outsourcer.

For companies that don't outsource, automation is important in staying competitive. For example, in an article from Transportation and Distribution, Nortel Networks found they couldn't reduce their total cost by implementing their own procurement system (Transportation \& Distribution, 1999). The new systems resulted in increased accuracy in packaging and inventory functions, and increase speed in the distribution system.

Nortel Networks was able to process package weight information, compute package and shipping cost, and create a carrier complaint label in less than four seconds (Transportation \& Distribution, 1999). The old system ran continuously just to keep up with demand, but the new system, can do the same job in sixteen hours, with 99.8\% accuracy (Transportation \& Distribution, 1999).

Managing warehouse systems can be improved through the use of software. Warehouse-management software systems are now available for online companies to purchase (Gilber, 1999). Companies such as EXE Technologies and Yantra are offering e-commerce order fulfillment packages (Gilber, 1999). These software packages can increase the efficiency by handling orders and tracking the delivery function. These are possible solutions that a company can do to implement automation in the company.

\section{Price}

Price is very important when dealing with e-commerce problems. Price can be a key issue when trying to increase demand or when decreasing demand. Price is definitely a weapon of choice by many companies (Holden, 1998). The two typical pricing methods are skimming and penetration. Skim pricing is charging a high price when the product is relatively new, in hope of making more profit. Penetration pricing is deployed to capture a large market share. The theory is based on creating a large market share, by being lower than competitors (Holden, 1998).

To increase demand, e-commerce companies need to focus on penetrating the market. This will work best for products that are in the introduction and growth stage (Holden, 1998). If the product is near the maturity stage, lowering the price won't increase profits very much. For relatively new products, offe ring the product below competitors will increase demand.

Pricing of a product can reduce demand without reducing profit. If an online company is doing very well, but isn't able to keep up with the current demand, it may be smart to actually raise the price of the product. This will do two things; it will keep profits at the same level, but allows the logistics department to handle the orders more efficiently. If companies can't keep up with demand, it will reduce the satisfaction of the customer, which will reduce the loyalty of the customer. A solution to keep customers happy is by reducing the demand through increasing the price, which will lower the number of purchases. Reducing the purchases will allow the company to match demand; in return it will be easier to keep current customers. It is believed that keeping current customers is five times cheaper than finding new ones (Haywood, 1989). When raising the price, it must be by a marginal amount, enough not to cause switching of loyal customers. Doing this will allow a company to keep the same profit and man- 


\section{New Marketing Strategy for E-Commerce}

age demand more efficiently. This solution may want to be done until the company can acquire an automated system.

Price bundling, which is packaging products together for one price (Kurtz, 1998). Using this tactic can be beneficial when doing business online. This can increase sales for a company, because customers feel the y are getting more value for their money. Increasing the value will reduce the risk for customers. Reducing the price by say $10 \%$, it can allow a company to increase sales. Sometimes this can be done with a product that is trying to be liquidated. This is a chance for the company to accomplish two things: increase sales and reduce unwanted inventory.

\section{Promotion}

Promotion is an important part when selling the product; it is a necessary function for e-commerce companies. This is one of the key facets in acquiring and keeping customers. Keeping and acquiring customers is important, but more attention and money needs to be spent on the place factors, such as warehousing and distribution functions (Foster, 1999). Some of the budget promotion money should be spent on developing better relations with distributors. Creating a strong bond with the delivery carriers will enhance the value of the company. This can be done through personal dealings with vendors. Doing such things as taking their representatives to events or to dinner can build a loyal relationship. These activities are inexpensive means that can really give an advantage to an e-commerce company.

Some troubles for e-commerce companies are the inability of customers to find the web page. If they can't find the web page, it creates a barrier in achieving increased sales. The current technology of search engines, such as Yahoo and Excite, are very broad in nature (Mardesich, 1999). When looking for a specific company it will bring up a vast variety of topics. It takes a while to narrow down the possible entries to find the intended company (Mardesich, 1999). Reducing the time spent looking for a web site can increase the satisfaction of the customers. If they must spend twenty minutes looking for a particular site, they may stop before they find it. A company can use promotion to combat these problems.

The best way to combat the problem is using promotions that give the web site address. If the product is high involvement, using advertising that is in magazines and newspapers should be efficient. For high involvement goods, people actively search for possible solutions to their problem. If the product is low involvement, people will not be actively searching for the product, so promotional activities must be intense. This can be accomplished by getting a large number of advertisements into television and radio vehicles.

Another possible promotional vehicle is using hyperlinks (Wehling, 1996). Hyperlinks allow a direct passage form another web site. This makes it very easy to find a particular web site. Hyperlinks are us ually most efficient when implemented on a web site of similar material.

In addition, there is no need to alienate customers or potential customers through promotional tactics. False or unethical marketing as become an issue in recent years, it isn't uncommon to find many of these web sites. This can be just puffery or it can be full blown bait-and-switch tactics.

Buy.com has built a reputation in participating in false advertising on their web site (Foster, 1999). This is definitely something e-commerce companies need to get away form. With growing popularity of ecommerce, the more this is done the more it will create havoc in the future. With increase volume in online buying, there will be more restrictions and patrolling of false and unethical promotions. With increase in online buyers, it will increase the importance of word-of-mouth communications, which can cause problems. Doing this type of promotion will decrease the confidence and loyalty of customers, which will reduce sales in the future. A company's profit is directly related to cus tomer loyalty, and 
these types of promotions will decrease loyalty. The question is clear, do they want to make a profit in the short run or be able to make a profit in the long run?

\section{Conclusion}

It is obvious there is a huge market in e-commerce, and there is a definite need for effective management. The only way for a company online to be successful in the long run is dealing with problems and making corrections. With many barriers involved in e-commerce, companies must be able to effectively and efficiently manage each phase of the marketing mix. Companies can't afford to just focus on two or three areas. This is not enough. Focusing on just product and place, will not accomplish goals in the long run. Each component must be evaluated periodically and managed effectively. The reason why evaluating each phase periodically, is that with such a diverse and technology driven area, elements are constantly changing. Scanning the environment is a must to stay competitive and efficient. In conclusion, the company can only be as good as its weakest link, each area is as important as the other is, integration among the four areas is vital.

\section{References}

Automated shipping streamlines the supply chain. (1999, October). Transportation \& Distribution, pp.16-19.

Ayers, A. F. (1999, September). What logistics managers need to know about today's complex information. Transportation \& Distribution, pp. 33-36.

Checking out. (2000, March-April). Harvard Business Review, p.22.

Foster, T. (1999, October). Dot-com retailers give 3PLs their big chance. Logistics Management \& Distribution, p. 38.

Foster, T. (1999, May 3). Dubious marketing ploys at buy.com expose the seamy side of e-commerce. Infoworld, p. 99.

Gilber, A. (1999, October 25). Fulfilling expectations. InformationWeek, pp. 22-23.

Haywood, K. M. (1989, Spring). Managing word of mouth communications. Journal of Services Marketing, p. 57.

Holden, R. K. \& Nagle, T. T. (1998, Summe r). Kamikaze pricing. Marketing Management, pp.31-34.

Jedd, M. (2000, February). Sizing up home delivery. Logistics Management \& Distribution Report, p.51.

Kurtz, D.L. \& Clow K.E. (1998). Services marketing. New York, John Wiley \& Sons, Inc. pp.11, 251.

Mardesich, J. (1999, November 8). The web is no shopper's paradise. Fortune, pp.188-190.

Pallab, P. (1996, Fall). Marketing on the internet. Journal of Consumer Marketing, pp.27-28.

Wehling, B. (1996, January 1). The future of marketing: What every marketer should know about being online. Vital Speeches of the Day, pp.170-173.

Wilder, C. (1998, December 7). E-commerce myths \& realities. Informationweek, pp.52-53.

Wilson, T. (1999, October 25). Shippers repackaged as e-provides. Informationweek, pp. 63-85.

\section{Biography}

Choong Y. Lee is a Professor of Management at Pittsburg State University, Pittsburg, KS, U.S.A. He received his B.Sc. in Engineering from Seoul National University, Korea, his M.S. in Industrial and Management Engineering, another M.S. in Applied Mathematics and Ph.D. in Business Administration all from the University of Iowa. His areas of research include operations strategy, JIT/TQM, supply chain management, technology management, and international management. He has published more than hundred articles in major journals and conference proceedings from all over the world. He has been invited as a guest speaker to many professional meetings internationally as well as domestically. 